\title{
Consolidation of gas hydrate-bearing sediments with hydrate dissociation
}

\author{
Maria De La Fuente ${ }^{1, *}$, Jean Vaunat $^{2}$, and Hector Marín-Moreno ${ }^{3}$ \\ ${ }^{1}$ International Center for Numerical Methods in Engineering, C. Gran Capitan SN, 08034 Barcelona, Spain. \\ ${ }^{2}$ Department of Civil and Environmental Engineering, Universitat Politècnica de Catalunya, 08034 Barcelona, Spain. \\ ${ }^{3}$ National Oceanography Centre, University of Southampton Waterfront Campus, European Way, Southampton SO14 $3 Z$ H, UK.
}

\begin{abstract}
Quantifying sediment deformation induced by depressurization of gas hydrate reservoirs and hydrate dissociation is crucial for the safe and economic production of natural gas from hydrates, and for understanding hydrate-related natural geological risks. This study uses our recently developed fully-coupled Thermo-Hydro-Mechanical formulation for gas hydrate-bearing geological systems implemented in the 3D Code_Bright simulator. First, the model formulation is briefly presented. Then, the model is applied to reproduce published experimental consolidation tests performed on hydrate-bearing pressure-core sediments recovered from the Krishna-Godavari Basin (offshore of India) during the India National Gas Hydrate Project Expedition 02 (NGHP02). The numerical simulation reproduces the tests in which the sediment is loaded and unloaded prior and after hydrate dissociates via depressurization at constant effective stress. Our results successfully capture sediment collapse when hydrate dissociates at a mean effective stress above that of the host sediment consolidation curve. The mechanical constitutive model Hydrate-CASM also allows reproducing the experimentally observed changes in sediment swelling index with changes in hydrate saturation.
\end{abstract}

\section{Introduction}

Gas production from gas hydrate bearing sediments (GHBS) has attracted international interest because of its potential to meet growing global energy demand and ensure energy self-sufficiency to countries that lack conventional reserves but have gas hydrate accumulations within their exclusive economic zones (e.g., Japan, India, and South Korea). However, gas production from hydrate has never been performed on a commercial scale partly because of, from a technical perspective, the geomechanical complexity associated with hydrate dissociation $[1,2]$.

Hydrate dissociation into gas and liquid water causes changes on the mechanical and hydraulic properties of the sediment that may compromise the stability of the reservoir and cease the well-bore productivity $[3,4]$. Assessing the mechanical stability of GHBS in the vicinities of gas production wells is a key design consideration in planning safe hydrate-sourced gas production. However, to do so, it is imperative to ascertain both the effect of changes in hydrate saturation on the mechanical response of the sediment and those related to the production method used to trigger hydrate dissociation (i.e., depressurization, thermal stimulation or chemical inhibition).

Over the past two decades, the mechanical properties of GHBS have been extensively studied at laboratory and field scale on specimens with constant hydrate saturation.
These studies have determined that hydrate favours the sediment to behave as a denser or cemented sediment exhibiting greater stiffness, strength, and dilatancy with respect to those of the hydrate-free sediment $[5,6]$. Recent experimental advancements have allowed to examine the behaviour of GHBS subjected to hydrate dissociation. Of particular interest are those tests evaluating the mechanical behaviour of GHBS dissociated via depressurization, which is deemed the most efficient approach for gas production from hydrate [7]. These tests evidence that volumetric deformation of GHBS is the result of both (i) the reduction in the sediment stiffness and strength with decreasing hydrate saturation and (ii) the increase in effective stress caused by the pore pressure drop imposed during depressurization [8-9].

From a geotechnical perspective, the depressurization method is equivalent to an isotropic consolidation stage, so that the increase in effective stress generates a reduction in void space. Recent reservoir simulations investigating the productivity of gas production from hydrates using depressurization indicate that production in deep-water systems would require a pore pressure decrease in excess of $10 \mathrm{MPa}[10,11]$.

Yoneda et al. [12] examined the effect of sediment compressibility on the viability of gas production by measuring permeability changes prior and after applying high effective stress in hydrate-bearing pressure cores. As a result of both the increase in effective stress during depressurization and consequent hydrate dissociation the

\footnotetext{
* Corresponding author: mdlf1g15@gmail.com
} 
sediment void ratio is reduced enough to drive the permeability of the hydrate-free sediment below the initial levels measured, even lower than when hydrate was occupying the pores, which hinders gas production. On the other hand, Yoneda et al. [13] investigated the consolidation properties and hardening behaviour of similar specimens through several oedometer and isotropic loading-unloading tests. Their results reveal that hydrate occurrence decreases the sediment compression and swelling indexes. In addition, they demonstrated that hydrate dissociation induces the GHBS to collapse towards the host sediment consolidation curve.

These findings demonstrate that sediment consolidation is an important aspect influencing both the rate of gas production and mechanical integrity of the system. To validate the capability of the Thermo-HydroMechanical (THM) formulation developed by De La Fuente et al. [14] at reproducing the consolidation response of GHBS, this paper uses some of the isotropic loading-unloading tests conducted by Yoneda et al. [13]. The simulations are conducted using the elasto-plastic constitutive model Hydrate-CASM [15] whose formulation reduces to one the number of empirical hydrate-dependent parameters and has been validated at reproducing triaxial compression tests in hydrate-bearing sands with a wide range of hydrate saturations and different hydrate morphologies.

\section{Modelling framework}

De La Fuente et al. [14] formulation extends the governing equations of energy and mass conservation of the 3D finite element simulator Code_Bright [16] to incorporate the most dominant processes related to having hydrate as a new pore phase. The formulation uses the constitutive model Hydrate-CASM [15] to simulate the mechanical response of the sediment, and the PengRobinson equation of state [17] and the thermodynamic equations proposed by Tishchenko et al. [18] to compute methane gas density and solubility, respectively. A detailed description of the formulation and governing equations can be found in the referred paper.

\subsection{Components, phases and volumetric relations}

The formulation follows a multicomponent and multiphase approach to describe the GHBS system. The porous medium is composed by four mass components; mineral grains $\left(g_{r}\right)$, methane $(m)$, water $(w)$, and salt $\left(s_{t}\right)$, that can be partitioned among four possible phases; solid $(s)$, hydrate $(h)$, gas $(g)$ and liquid $(l)$. The mineral grains form the non-reactive solid continuum that provides the skeletal structure to the porous medium. Within the pores, hydrate can grow as a non-permanent solid and immobile phase (Figure 1). Finally, fluid flow and storage are restricted to the available space between the mineral grains and the hydrate phase.

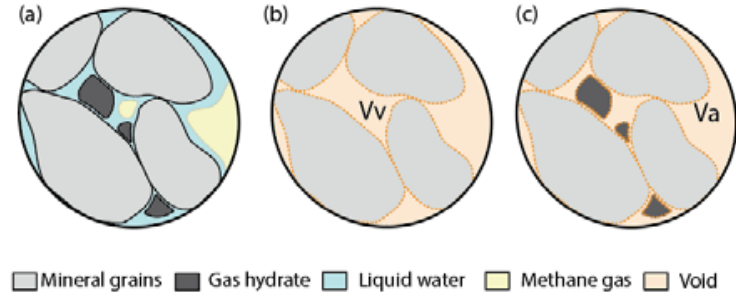

Fig. 1. (a) Pore-scale distribution of the possible phases considered in the model, (b) potential void volume and (c) available void. Note that $V_{v}=V_{a}$ in the absence of hydrate. Adopted from [14].

The void-space is divided into potential void volume $\left(V_{v}\right)$ and available void volume $\left(V_{a}\right)$. The potential void volume is the void space between the mineral grains of the sediment and includes the available void volume for fluid flow and storage and the hydrate volume. This volumetric distinction is key to isolate mechanical changes caused by effective stress changes only from those related to hydrate phase change on both the hydraulic and mechanical properties of the porous medium.

\subsection{Mechanical model for GHBS}

We use the elasto-plastic model Hydrate-CASM [15], which extends the formulation of the critical state model CASM [19] by implementing the subloading surface model [20] and introducing the densification mechanism. Alternatively to previous models for GHBS, the HydrateCASM does not rely on physical bonding between hydrate crystals and sediment grains, but on the densification effect that pore invasion with hydrate has on the mechanical properties of the sediment. In particular, the model suggests that the decrease of the sediment available void volume due to hydrate formation stiffens its structure and has a similar mechanical effect as the increase of the host sediment density.

\subsubsection{Hydrate-CASM subloading function}

The Hydrate-CASM model incorporates the subloading surface concept [20] to capture irrecoverable, plastic strains inside the general CASM yield surface. The formulation assumes the existence of a homothetic subloading surface to the CASM yield surface that can expand/contract inside it. The Hydrate-CASM subloading function is derived from the CASM formulation as:

$$
f=\left(\frac{q}{M p^{\prime}}\right)^{n}+\frac{1}{\ln (r)} \ln \left(\frac{p^{\prime}}{R p^{\prime} 0}\right)
$$

Where $p^{\prime}$ is the mean effective stress, $q$ is the deviatoric stress, $M$ is the slope of critical state line in the $p^{\prime}-q$ space, $n$ and $r$ are model parameters defining the shape and size of the CASM yield surface and $R$ is the subloading ratio, which controls the size of the subloading surface $\left(R=\frac{p_{0 S}^{\prime}}{p_{0}^{\prime}}\right)$ and recovers the original CASM yield function for values equal to 1 . The evolution of $R$ is 
controlled by the norm of the incremental plastic strain vector $\left(\left|d \varepsilon^{p}\right|\right)$ and the subloading parameter $u$ as follows:

$$
d R=-u \ln R\left|d \varepsilon^{p}\right|
$$

To demonstrate the importance of considering the subloading surface when modelling sediment volumetric yielding, the consolidation curve of Toyoura sand is simulated in Figure 2 . The yielding stress $\left(p_{0}^{\prime}\right)$, compression slope in the high-pressure region $(\lambda)$, and the swelling slope $(\kappa)$ adopted in the simulation (Table 1) calibrated from the experimental data. The rest of critical state parameters characterizing the mechanical behaviour of sediment are adopted from a previous publication simulating the mechanical response of Toyoura sand [15].

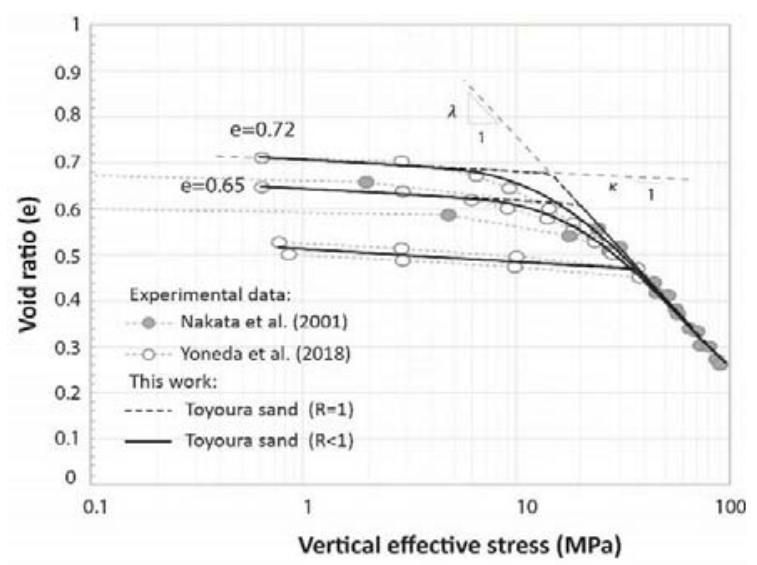

Fig. 2. Influence of the subloading surface on changes in Toyoura sand void ratio during one-dimensional consolidation. Experimental data from [13] and [21].

The simulations presented in Figure 2 show the importance of the subloading surface to capture the smooth transition observed experimentally between the elastic and plastic behaviour during one-dimensional consolidation of Toyoura sand.

Table 1. Input parameters for modelling Toyoura sand consolidation curve. Note that $p_{0}^{\prime}$ decreases with increasing the initial void ratio of the specimen for the two loadingunloading tests simulated.

\begin{tabular}{c}
\hline Toyoura sand input parameters \\
\hline Slope of compression line $(\lambda): 0.22$ \\
Slope of swelling line $(\kappa): 0.011$ \\
Pre-yield plasticity rate $(u): 20$ \\
Isotropic yield stress subloading surface \\
$\left(p^{\prime}{ }_{0 s}, M P a\right): 3.5$ \\
\hline Initial void ratio $(e): 0.65$ \\
Isotropic yield stress CASM yield surface \\
$\left(p^{\prime}, M P a\right): 20$ \\
Subloading ratio $(R): 0.175$ \\
\hline Initial void ratio $(e): 0.72$ \\
Isotropic yield stress CASM yield surface \\
$\left(p_{0}^{\prime}, M P a\right): 15$ \\
Subloading ratio $(R): 0.23$
\end{tabular}

\subsubsection{Densification mechanism}

The densification mechanism introduced by De La Fuente et al. [15] suggests that the occurrence of hydrate as a solid phase invading the sediment void volume has a similar mechanical effect as the increase of the host sediment density. In particular, the model attributes stress-strain changes observed in GHBS to variations in the sediment available void volume, $\kappa$ and, $p_{0}^{\prime}$ with hydrate saturation $\left(S_{h}\right)$.

The Hydrate-CASM uses the available void ratio left after hydrate formation (Figure 1c) to derive the mechanical properties of the GHBS:

$$
e_{a h}=e\left(1-S_{h}\right)=e-e_{h}
$$

where $e$ is the host sediment void ratio at the moment in which the hydrate is formed, $e_{h}$ is the void ratio occupied by hydrate and $e_{a h}$ is the resulting available void ratio of the hydrate-bearing sediment.

In addition, the model considers the stiffening effect that hydrate has in the elastic response of the sediment [22] by relating the swelling line slope of the host sediment $(\kappa)$ to $S_{h}$. So that the swelling line slope of the hydrate-bearing sediment $\left(\kappa_{h}\right)$ reads as:

$$
\kappa_{h}=\kappa \kappa_{r f}
$$

where the reduction factor $\left(\kappa_{r f}\right)$ is calibrated empirically as:

$$
\kappa_{r f}=\left\{\begin{array}{c}
1 \text { if } S_{h}=0 \\
3\left(S_{h}\right)^{2}-2.69 S_{h}+0.9934 \text { if } 0<\mathrm{S}_{\mathrm{h}}<0.42 \\
0.397 \text { if } \mathrm{S}_{\mathrm{h}}>0.42
\end{array}\right.
$$

As a result of both the decrease of the host sediment available void ratio and the increase of stiffness with $S_{h}$, the model predicts an increase of the sediment isotropic yield stress that can be derived graphically in the $v-$ $\ln \left(p^{\prime}\right)$ space by projecting $e_{a h}$ on the normal consolidation line of the host sediment (NCL) following the $\kappa_{h}$ slope (Figure 3a), so that:

$$
\frac{p_{0 h}^{\prime}}{p_{\text {ref }}^{\prime}}=\exp \left(\frac{e_{h}}{\lambda-\kappa_{h}}\right)\left(\frac{p_{0}^{\prime}}{p_{\text {ref }}^{\prime}}\right)^{\left(\frac{\lambda-\kappa}{\lambda-\kappa_{h}}\right)}
$$

where $p_{\text {'ref }}$ refers to the mean effective pressure at which hydrate is formed and changes in $p^{\prime}{ }_{0 h}$ are computed through $d p^{\prime}{ }_{0}$, which similarly to Cam-clay type models is assumed to be controlled by the incremental plastic volumetric strain $\left(d \varepsilon_{v}^{p}\right)$ :

$$
d p_{0}^{\prime}=\frac{\left(1+e_{a h}\right) p_{0}^{\prime}}{\lambda-\kappa} d \varepsilon_{v}^{p}
$$



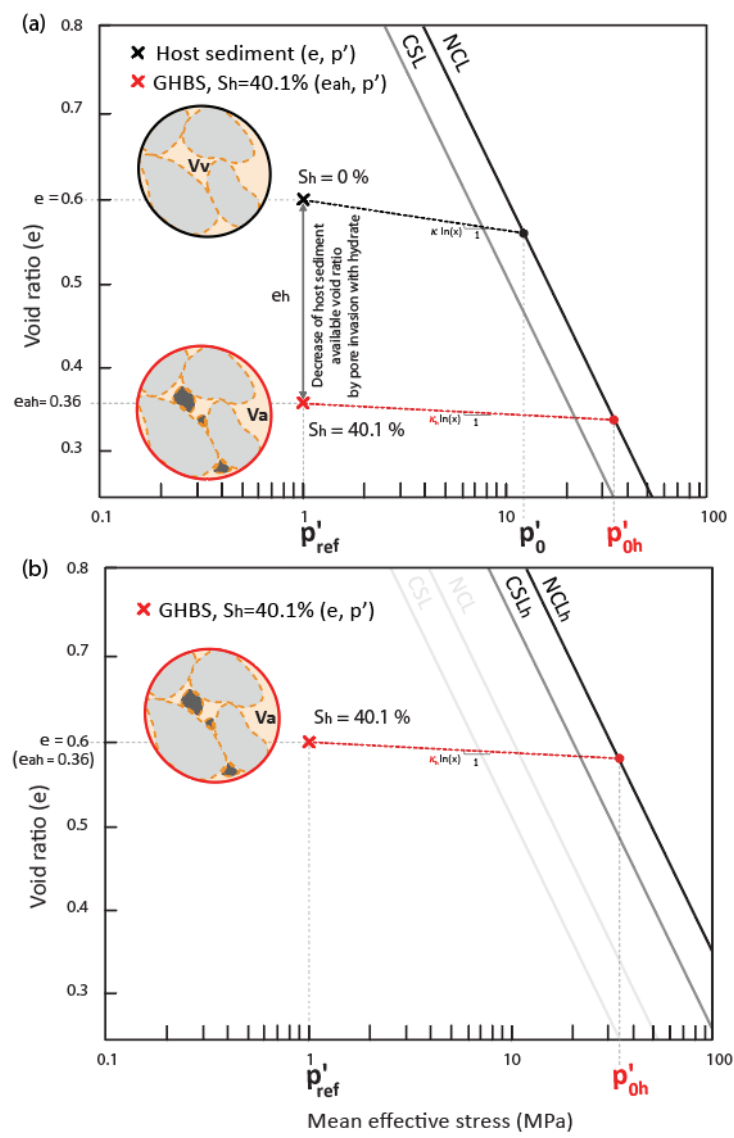

Fig. 3. Influence of the densification and stiffening effects caused by hydrate formation at (a) predicting the isotropic yield stress of GHBS and (b) shifting the normal consolidation and critical state line of the sediment. Modified from [15].

\subsubsection{GHBS critical state}

The densification mechanism has a clear effect on the critical state of GHBS. When relating the actual potential void ratio of the sediment $(e)$ with the predicted $p^{\prime}{ }_{0 h}$, both the normal consolidation and critical state lines $(C S L)$ of the sediment are shifted parallel to those of the host sediment (Figure 3b). Note that $N C L_{h}$ and $C S L_{h}$ recover $N C L$ and $C S L$ when hydrate dissociates completely.

Figure 4 examines the effect of $S_{h}$ on the critical state of the sediment by simulating the consolidation curve of Toyoura with $20 \%$ of hydrate saturation. The simulation shows that the model predicts a consolidation curve that is higher than that of the host sediment and reproduces a hardening of the sediment swelling index with increasing $S_{h}$, as it has been observed experimentally by Yoneda et al. [13].

Note that the simulated curve in Figure 4 reach effective stress at which mass particle crushing might be occurring (this phenomenon is estimated to begin between 10 and $20 \mathrm{MPa}$ of effective stress [21]). However, the constitutive model used in this paper does not consider the mechanical effect of particle crushing and assumes that, as suggested experimentally by [23], the presence of gas hydrate in sediments could mitigate it.

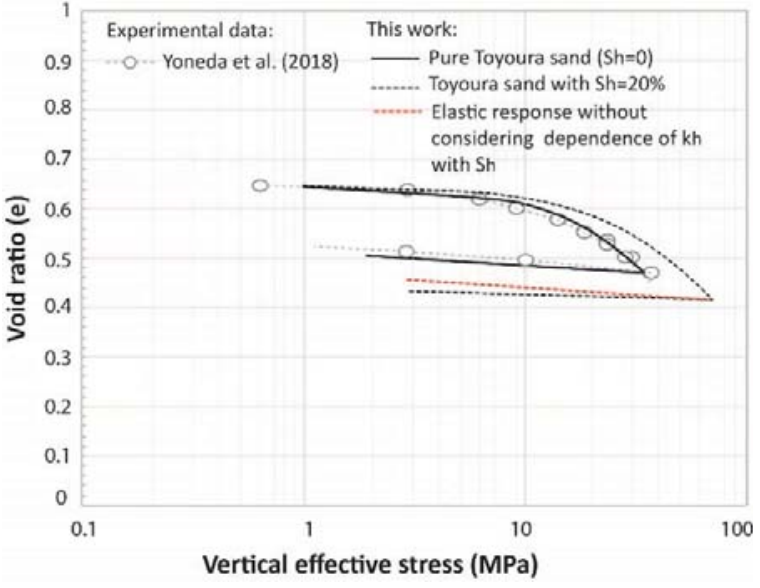

Fig. 4. Effect of hydrate saturation on Toyoura sand consolidation curve. Experimental data from [13].

\section{Model application}

Yoneda et al. [13] examine the consolidation and hardening characteristics of the hydrate-bearing pressurecore sediments recovered during the NGHP02 expedition. Their study conducts several isotropic loading-unloading consolidation tests on sandy-silts with hydrate saturations ranging from $32-72 \%$. The major goal of these tests was to evaluate differences in the compression and swelling characteristics of hydrate-bearing sediments prior and after hydrate dissociation, as well as to capture the volumetric response of the specimen during hydrate dissociation triggered by depressurization at constant effective stress.

Three of the isotropic consolidation tests presented in [13] have been selected in this paper to examine the capabilities of the THM formulation at reproducing the consolidation characteristics of natural GHBS. The tests consist on four main stages, starting with unloading the specimens from the in-situ effective stress $\left(p^{\prime}\right)$ of $1 \mathrm{MPa}$ to $p^{\prime}=0.2 \mathrm{MPa}$. Then, specimen 16B-3P (274.13-274.23) is reloaded to $p^{\prime}=1 \mathrm{MPa}$, while specimens $16 \mathrm{~B}-3 \mathrm{P}$ (274.03-274.13) and 16B-7P (287.12-287.20) are loaded up to $p^{\prime}=5 \mathrm{MPa}$. After the consolidation step, gas hydrate is dissociated by depressurization from 10 to $1 \mathrm{MPa}$ keeping constant the effective stress. Finally, the hydratefree specimens are further consolidated to $p^{\prime}=12 \mathrm{MPa}$.

\subsection{Host sediment calibration}

To predict the mechanical behaviour of GHBS is crucial to determine the response of the corresponding host sediment. The consolidation data from specimen 16B-3P (274.13-274.23) after hydrate dissociation (Figure 5) is used here to calibrate the input parameters that characterize the mechanical behaviour of the host sediment (Table 2). 


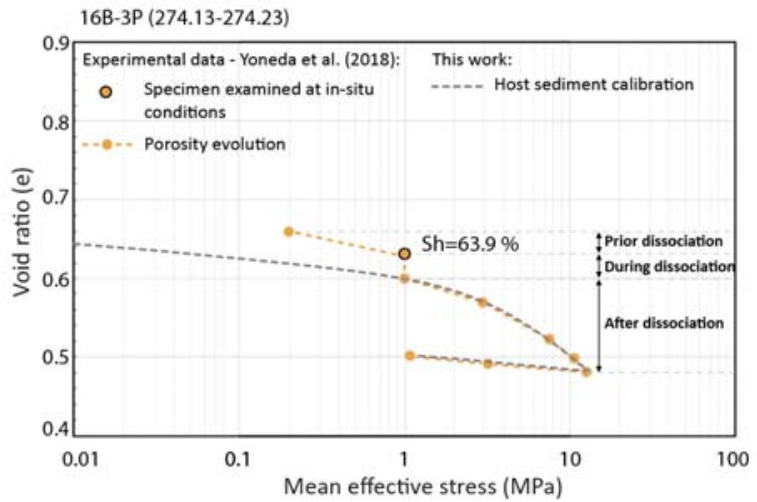

Fig. 5. Calibration of the host sediment mechanical response during isotropic consolidation after dissociation. Experimental data from [13].

Note that the calibration considers $p^{\prime}=0.01 \mathrm{MPa}$ as initial effective stress to account for the geological story of the sediment and that $\lambda$ and $\kappa$ are estimated graphically adopting similar values to those reported in Yoneda et al. [13]. In addition, differences in the in-situ void ratio reported for the specimens examined here (i.e., 16B-3P (274.13-274.23) $e=0.63$, 16B-3P (274.03-274.13) $e=$ 0.66 and 16B-7P (287.12-287.20) $e=0.7)$ and its corresponding effect on $p_{0}^{\prime}$ are also considered in the simulation (Table 3).

Table 2. Input parameters for modelling the consolidation curve of specimen 16B-3P (274.13-274.23) after hydrate dissociation.

Host sediment input parameters 16B-3P (274.13-274.23)

Initial void ratio $(e)$ 0.65

Slope of compression line $(\lambda)$ 0.087

Slope of swelling line $(\kappa)$ 0.0087

Pre-yield plasticity rate $(u)$ 50

Isotropic yield stress CASM yield surface $\left(p_{0}^{\prime}, M P a\right)$

Isotropic yield stress subloading surface $\left(p_{0 s}^{\prime}, M P a\right)$

0.1

Subloading ratio $(R)$

\subsection{Hydrate mechanical contribution}

The triaxial tests conducted by Yoneda et al. [12] on similar NGHP02 specimens evidence an increase in the sediment strength and stiffness, as well as a positive dilatancy, with increasing $S_{h}$, which support previous research on laboratory-formed and natural GHBS. However, the increase in the sediment strength with hydrate in these specimens was encountered low in comparison to past published mechanical data from GHBS. This low strength can be explained by the small particle size and loose packing of the host sediments recovered as well as to the relatively slow compression strain rate used in the majority of the tests $(\sim 0.01 \% / \mathrm{min})$ [12].

Table 3. Initial void ratio and isotropic consolidation pressure used to model specimens 16B-3P (274.03-274.13) and 16B-7P (287.12-287.20). Note that the rest of input parameters from Table 2 are kept for the modelling.

Host sediment input parameters 16B-3P (274.03-274.13)

\begin{tabular}{lc}
\hline Initial void ratio $(e)$ & 0.68 \\
Isotropic yield stress CASM yield surface $\left(p^{\prime} \circ, M P a\right)$ & 2.65 \\
Subloading ratio $(R)$ & 0.0376
\end{tabular}

Host sediment input parameters 16B-7P (287.12-287.20)

Initial void ratio $(e)$ 0.72

Isotropic yield stress CASM yield surface $\left(p^{\prime} 0, M P a\right)$ 1.59

Subloading ratio $(R)$

0.0628

To calibrate the low contribution of $S_{h}$ observed on the sediment strength, we introduce an empirical hydratedependent parameter $(\alpha)$ in the Hydrate-CASM formulation. This parameter allows adjusting the corresponding hydrate fraction effectively contributing to the mechanical response of the sediment, so that Eq. 3 reads:

$$
e_{a h}=e\left(1-S_{h_{m e c}}\right)=e-e_{h_{m e c}}
$$

where $S_{h_{m e c}}$ is defined as:

$$
S_{h_{m e c}}=S_{h} \alpha
$$

Parameter $\alpha$ ranges from 0 when the presence of hydrate is not impacting the mechanical behavior of the sediment to 1 when the mechanical contribution of the hydrate is considered equivalent to the solid matrix (as considered previously in [14] and [15]). The use of a reduced mechanical contribution of hydrate (i.e., $\alpha<1$ ) could be physically justified in cases where a significant proportion of small hydrate grains is well distributed floating in pores, without adding additional strength (no additional grain contacts), neither much kinematic constrains (small grains), or densification (microporous hydrate).

For the simulations presented here $\alpha$ has been calibrated to a value of 0.22 , based on the experimental data from specimen 16B-7P (287.12-287.20) (consolidation curve of the hydrate-bearing sediment prior dissociation in Figure 6a). Then, the THM formulation is applied to simulate changes in the sediment void ratio induced by isotropic consolidation and hydrate dissociation.

Figure 6 shows that the model results successfully match the experimental data, predicting (i) an accurate evolution of the sediment void ratio during isotropic loading prior and after hydrate dissociation, (ii) sediment collapse to the host sediment consolidation curve due to hydrate 
dissociation and (iii) suitable changes in the sediment swelling index with variations in $S_{h}$.

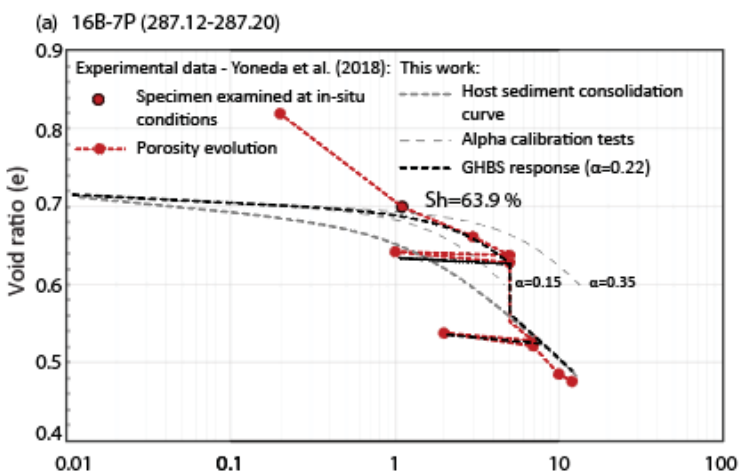

(b) $16 \mathrm{~B}-3 \mathrm{P}(274.03-274.13)$

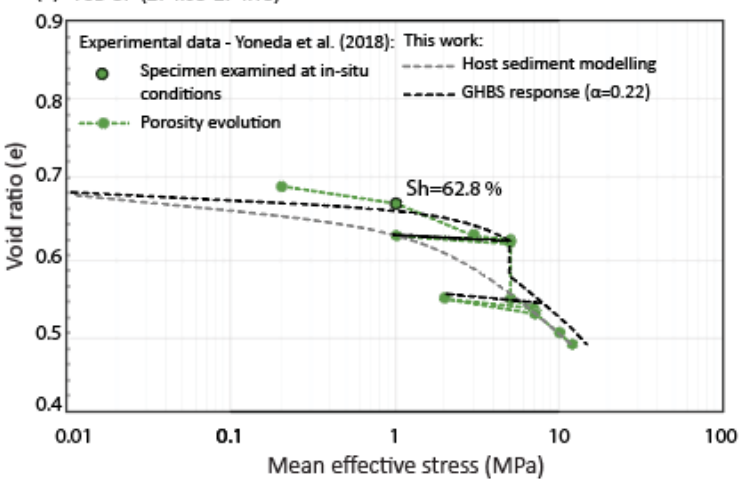

Fig. 6. Model results versus consolidation data with dissociation from specimens (a) 16B-7P (287.12-287.20) and (b) 16B-3P (274.03-274.13). Experimental data from [13].

\section{Summary}

This paper presents an overview of the fully-coupled THM formulation developed by De La Fuente et al. (2019) and its application to the isotropic consolidation tests with dissociation conducted by Yoneda et al. (2018) on hydrate-bearing pressure-core sediments recovered from the Krishna-Godavari Basin. This paper introduces a modification on the mechanical model considered in the THM formulation to adjust the corresponding hydrate fraction effectively contributing to the mechanical response of the sediment. The results evidence the capacity of the formulation to reproduce the main features observed in the compression and swelling behaviour of GHBS subjected to isotropic loading and unloading, as well as sediment collapse to the host sediment consolidation curve induced by hydrate dissociation.

\section{References}

1. J. L. H. Grozic, Interplay Between Gas Hydrates and Submarine Slope Failure. In Advances in Submarine Mass Movements and Their Consequences, 28 (2010)

2. S. Uchida, J.S Lin, E.M. Myshakin, Y. Seol, R. Boswell, Numerical simulations of sand migration during gas production in hydrate-bearing sands interbedded with thin mud layers at site NGHP-0216. J. Mar. Pet. Geol., 188:639-647 (2019)

3. J. Nimblett, R. Shipp, and F. Strijbos, Gas hydrate as a drilling hazard: Examples from global deep-water settings. Proceedings of Offshore Technology Conference (2005)

4. S. Uchida, A. Klar, K. Yamamoto, and production model in gas hydrate-bearing sediments. Int. J. Rock Mechanics and Mining Sci., 86;303-316 (2016)

5. W. Waite, J. Santamarina, D. Cortes, B. Dugan, N. Espinoza et al., Physical properties of hydratebearing sediments. Reviews of Geophysics, 47 (2009)

6. B. Madhusudan, C. Clayton and J. Priest, The effects of hydrate on the strength and stiffness of some sands. J.G.R, 1(18) (2018)

7. M.D. Max, A.H. Johnson, Exploration and Production of Oceanic Natural Gas Hydrate: Critical Factors for Commercialization. Springer International Publishing, 155 (2019)

8. M. Hyodo, J. Yoneda, N. Yoshimoto and Y. Nakata, Mechanical and dissociation properties of methane hydrate-bearing sand in deep seabed. Soils and Foundations, 53(2):299-314 (2013)

9. D. Li, Q. Wu, Z. Wang, J. Lu, D. Liang, and X. Li, Tri-axial shear tests on hydrate-bearing sediments during hydrate dissociation with depressurization. Energies, 11:1819 (2018)

10. R. Boswell, E. Myshakin, G. Moridis, Y. Konno, T.S. Collett, M. Reagan, T. Ajayi, Y. Seol, India National Gas Hydrate Program Expedition 02 summary of scientific results: Numerical simulation of reservoir response to depressurization. J. Mar. Pet. Geol., 108:154-166 (2019)

11. Y. Konno, A. Kato, J. Yoneda, M. Oshima, M. Kida, Y. Jin, J. Nagao, N. Tenma, J. Numerical Analysis of Gas Production Potential from a Gas-hydrate Reservoir at Site NGHP-02-16, the KrishnaGodovari Basin, Offshore India - Feasibility of Depressurization Method for Ultra-deepwater Environment. Mar. Pet. Geol., 108:731-740 (2018)

12. J. Yoneda, M. Oshima, M. Kida, A. Kato, Y. Konno, Y. Jin, J. Jang, W.F. Waite, P. Kumar, N. Tenma, Permeability variation and anisotropy of gas hydrate-bearing pressure-core sediments recovered from the Krishna-Godavari Basin, offshore India. J. Mar. Pet. Geol., 108:524-536 (2018)

13. J. Yoneda, A. Masui, Y. Konno, Y. Jin, M. Kida, J. Katagiri, J. Nagao, N. Tenma, Consolidation and hardening behavior of hydrate-bearing pressure-core sediments recovered from the Krishna-Godavari Basin, offshore India. J. Mar. Pet. Geol. 108, 512523 (2018)

14. M. De La Fuente, J. Vaunat, H. Marín-Moreno, Thermo-Hydro-Mechanical Coupled Modeling of Methane Hydrate-Bearing Sediments: Formulation and Application. Energies, 12, 2178 (2018) 
15. M. De La Fuente, J. Vaunat, H. Marín-Moreno, A densification mechanism to model the mechanical effect of methane hydrates in sandy sediments. Int. J. Numer. Anal. Methods Geomech.,1-21 (2019)

16. S. Olivella, A. Gens, J. Carrera, and E.E. Alonso, Numerical formulation for a simulator (code-bright) for the coupled analysis of saline media. Engineering Computations, 13(7):87-112 (1996)

17. D. Y, Peng and D. B. Robinson, A new two-constant equation of state. Industrial and Engineering Chemistry Fundamentals, 1(15):59-64 (1976)

18. P. Tishchenko, C. Hensen, K. Wallmann and C. S. Wong, Calculation of the stability and solubility of methane hydrate in seawater. Chemical Geology 219 (1-4); 37-52 (2005)

19. H. Yu, CASM: a unified state parameter model for clay and sand. Int. J. Numer. Anal. Methods Geomech., 22(8):621-653 (1998)

20. K. Hashiguchi, Subloading surface model in unconventional plasticity. J. Petroleum Sci. and Engineering, 25(8):917-945 (1989)

21. Y. Nakata, Y. Kato, M. Hyodo, A.F.L Hyde, H. Murata, One-dimensional compression behaviour of uniformly graded sand related to single particle crushing strength. Soils Found. 41, 39-51 (2001)

22. J. A. Priest, A laboratory investigation into the seismic velocities of methane gas hydrate-bearing sand. J. G. R, 110(B4):1-13 (2005)

23. J. Kim, S. Dai, J. Jang, W.F. Waite, T.S. Collett, P. Kumar, Compressibility and particle crushing of Krishna-Godavari Basin sediments from offshore India: Implications for gas production from deepwater gas hydrate deposits, Marine and Petroleum Geology, 108:697-704 (2019) 